\title{
KINERJA TIM SERBU API KELURAHAN (TSAK) DALAM PENANGGULANGAN KEBAKARAN HUTAN DAN LAHAN DI KECAMATAN SABANGAU KOTA PALANGKA RAYA
}

\section{Performance Of Fire Assault Team Village (TSAK) In Overcoming Forest Fire And Land In Sabangau Subdistrict Of Palangka Raya City}

\section{Ambar Ratmoko"}

Arbaini

\author{
Universitas Muhammadiyah \\ Palangkaraya, Palangka Raya, Central \\ Kalimantan, Indonesia
}

email:

ambar.ratmoko@umpalangkaraya.ac.id

\section{Kata Kunci:}

Kinerja

Tim Serbu Api

Kebakaran Hutan dan Lahan

\section{Keywords:}

Performance

Fire Assault Team

Forest fires and land

\begin{abstract}
Abstrak
Penelitian ini bertujuan untuk mengetahui kinerja Tim Serbu Api Kelurahan (TSAK) dalam penanggulangan kebakaran hutan dan lahan di Kecamatan Sabangau Kota Palangka Raya. Metode yang di gunakan adalah deskriptif kualitatif, sumber data primer dan sekunder, teknik pengumpulan data observasi, studi literatur dan wawancara.

Kinerja Tim Serbu Api Kelurahan (TSAK) di Kecamatan Sabangau Kota Palangka Raya masih belum maksimal yang di gambarkan oleh tujuh indikator sebagai berikut, Tujuan: Dalam pelaksanaan tugas masih belum tercapai sesuai harapan. Standar: Tim Serbu Api (TSAK) masih belum memiliki SOP sehingga sulit untuk mengetahui keberhasilan suatu pekerjaan. Umpan balik: Tidak adanya umpan balik maka sulit melakukan perbaikan kinerja. Alat/ sarana: masih kurang memadai. Kompetensi: sudah memiliki pengetahuan dan kehlian dalam melaksanakan tugas. Motif: Tidak ada kompensasi yang di janjikan baik dari segi materil maupun non materil. Peluang: belum ada harapan, karena TSAK dibentuk bukan sebagai profesi tetapi tujuan sebenarnya adalah sosial dan kemanusiaan. Adapun saran yang dapat di sampaikan kepada Badan Penaggulangan Bencana dan Pemadam Kebakaran (BPBPK) Kota Palangka Raya antara lain: diharapkan dapat membentuk/ menetapkan Standar Operasional Prosedur (SOP), menambah/ memperbaharui peralatan yang memadai, menetapkan upah yang layak/standar, serta mencari solusi/ kebijakan mengenai masa depan anggota TSAK.
\end{abstract}

\begin{abstract}
This research aims to determine the performance of the Village Fire Assault Team (TSAK) in response to forest fires and land in Sabangau sub-district Palangka Raya. The methods used are qualitative descriptive, primary and secondary data sources, observational data collection techniques, literature studies, and interviews.

Performance of Fire Assault Team Village (TSAK) in Sabangau Sub-district of Palangka Raya is still not maximally described by seven indicators as follows, objectives: in the implementation of the task is still not reached as expected. Standard: Fire Assault Team (TSAK) still does not have SOP so it is difficult to know the success of a job. Feedback: The absence of feedback is difficult to perform performance improvements. Tool/means: still insufficient. Competence: already has knowledge and Kehlian in carrying out the task. Motive: No compensation in the promised both in terms of material and nonmaterial. Opportunity: There has been no hope because TSAK was formed not as a profession but the real purpose is social and humanitarian. The advice that can be conveyed to the establishment of disaster and fire Fighting Agency (BPBPK) Palangka Raya City among others: is expected to form/establish standard operational procedure (SOP), add/renew adequate equipment, Set a decent/standard wage, as well as finding a solution/policy on the future of TSAK members.
\end{abstract}

\section{Accepted \\ January 2018 \\ Published \\ April 2018}

\section{PENDAHULUAN}

Sejarah terjadinya kebakaran hutan telah terjadi sejak ribuan tahun yang lalu, semula dianggap terjadi secara alami, tetapi manusia mempunyai peran dalam memulai kebakaran di milenium terakhir ini, pertama untuk memudahkan perburuan dan selanjutnya untuk membuka petak-petak pertanian di dalam hutan.

Di Kota Palangka Raya fenomena kebakaran hutan dan lahan hampir terjadi setiap tahun telah mengakibatkan kabut asap yang berkepanjangan dan berbagai dampak 
akibat dari kebakaran hutan dan lahan telah kita rasakan. Tidak terkecuali Kota Palangka Raya pada umumnya, Kecamatan Sabangau juga memberi andil besar dalam penyumbang asap akibat dari kebakaran hutan dan lahan yang telah kita rasakan hampir setiap tahunnya.

Kecamatan Sabangau memiliki 6 (enam) Kelurahan, sebagian besar memiliki struktur tanah bergambut tebal dan memiliki kedalaman hampi dua meter. Di Kecamatan Sabangau yang rata-rata struktur tanahnya bergambut tebal serta diatasnya banyak ditumbuhi semak belukar akan sangat rentan terhadap terjadinya kebakaran.

Berbagai kebijakan peraturan dan Perundang-Undangan yang berkaitan dengan masalah kebakaran hutan dan lahan telah dibuat oleh pemerintah, namun pada pelaksanaanya tidak sejalan dengan apa yang diharapkan. Berbagai pelanggaran dan ketidak patuhan terhadap larangan.

Pembakaran hutan dan lahan pada musim kemarau dapat kita temui berupa himbauan-himbauan dalam berbagai bentuk seperti spanduk, reklame dan sebagainya yang dibuat oleh pemerintah pada daerahdaerah rawan yang rentan terhadap bahaya kebakaran sering tidak diindahkan. Penanganan kebakaran hutan dan lahan bukan hanya tanggungjawab pemerintah saja, tetapi harus juga ada peranserta masyarakat yang terlibat didalamnya. Keterlibatan masyarakat sangatlah dibutuhkan oleh pemerintah, karena dengan terjalinnya kerjasama antara pemerintah dan masyarakat maka permasalah yang terjadi akan mudah dihadapi.

Pelibatan dan kesiapan masyarakat dalam pencegahan kebakaran hutan dan lahan diwujudkan dengan pembentukan Tim Serbu Api Kelurahan (TSAK) yang dibentuk berdasarkan Peraturan Daerah Kota Palangka Raya Nomor 07 Tahun 2003 Tentang Pencegahan dan Penanggulangan Kebakaran Hutan dan Lahan Di Wilayah Kota Palangka Raya. Tim Serbu Api Kelurahan atau disingkat TSAK adalah tim operasional dari satuan tugas penanggulangan kebakaran hutan dan lahan tingkat Kelurahan yang bertugas menanggulangi/memadamkan kebakaran hutan dan lahan di Wilayah Kota Palangka Raya. Keanggotaan Tim Serbu Api Kelurahan (TSAK) terdiri dari sekelompok orang yang terbentuk atas koordinasi Camat dan Lurah beranggotakan komponen masyarakat (TNI/Polisi, Tokoh masyarakat/Tokoh Agama, PPL/LSM/Ormas, Pengusaha, dan lain-lain) di Kelurahan yang tujuan dan kegiatannya dalam rangka penanggulangan kebakaran hutan dan lahan di Wilayah Kota Palangka Raya.

Menurut Rivai dan Basri (Sianambela, 2012:6), menyatakan kinerja adalah tingkat keberhasilan sesorang atau keseluruhan selama periode tertentu didalam melaksanakan tugas dibandingkan dengan berbagai kemungkinan, seperti standar hasil kerja, target atau sasaran atau kriteria yang telah ditentukan terlebih dahulu dan telah disepakati bersama.

Sebagai garda terdepan dan ujung tombak dalam penanganan kebakaran hutan dan lahan, TSAK berperan strategis dalam mengendalikan terjadinya kebakaran di wilayah kerjanya masing-masing. Kinerja organisasi ini sangatlah di butuhkan mengingat tugas dan fungsinya yang sangat strategis dalam hal melakukan pemadaman secara dini. Melihat peranannya yang sangat strategis dan efektif dalam pelaksanakan penanggulangan kebakaran hutan dan lahan diwilayah kerjanya masing-masing, maka kinerjannya sangatlah diperlukan. Hal tersebut dapat di rasakan pada awal Tim Serbu Api Kelurahan (TSAK) terbentuk, jumlah kebakaran hutan dan lahan sudah dapat di minimalisir sedini mungkin, dengan keberadaannya Tim Serbu Api Kelurahan telah diakui sangat efektif dalam hal melakukan pemadaman kebakaran hutan dan lahan, namun dalam perjalannya pada akhir-akhir tahun belakangan kebakaran hutan dan lahan hampir tidak terkedalikan.

Keaktifan Tim Serbu Api Kelurahan (TSAK) dalam pelaksanaan tugasnya di lapangan dalam menanggulangi 
kebakaran hutan dan lahan terlihat semakin berkurang, hanya sebagian yang masih aktif, sementara peranannya sangat diperlukan. Berbagai anggapan negatifpun muncul terhadap pemerintah, baik itu dari segi ketidak percayaan masyarakat sampai ketidak sanggupan pemerintah dalam menyelesaikan permasalahan kebakaran hutan dan lahan. Berdasarkan uraian tersebut di atas dan menyadari fungsi strategis dari TSAK, maka mendorong untuk membahas lebih lanjut.

\section{METODOLOGI}

Penelitian ini menggunakan metode kualitatif yang ingin mengggambarkan kinerja TSAK dalam penanggulangan kebakaran hutan dalahan di Kecamatan Sebangau. Dalam hal ini peneliti melakukan wawancara mendalam berkali-kali dengan berbagai teknik bertanya dan observasi berpartisipasi merupakan cara yang paling tepat. Metode penelitian kualitatif sangat diperlukan karena banyak hal yang tidak dapat ditelah dengan menggunakan metode kuantitatif. Data yang digunakan berasal dari informasi yang diperoleh dari Para Anggota Tim Serbu Api Kelurahan dan pihak-pihak yang relevan seperti Dinas Lingkungan Hidup dan Kehutanan Kota Palangkaraya, Badan Penanggulangan Bencanan dan Pemdan Kebakaran, Pemerintah Kota Palangka Raya serta data-data lain yang relevan dnegan masalah penelitian ini.

\section{HASIL DAN PEMBAHASAN}

Organisasi Tim Serbu Api Kelurahan (TSAK) Kota Palangka Raya berfungsi sebagai Tim Penanggulangan Kebakaran Hutan dan Lahan di Wilayah Kota Palangka Raya, khususnya melakukan penanggulangan kebakaran hutan dan lahan di Wilayah kerjanya masing-masing, yakni di mana lokasi atau daerah Kelurahan itu berada.

Tim Serbu Api Kelurahan (TSAK) Kota Palangka Raya bertugas: a. Melakukan Pencegahan, yakni memonitoring atau melakukan pengawasan di daerah atau lokasi lahan yang rentan terhadap bahaya kebakaran di wilayah kerjanya masing-masing.

b. Melakukan pemadaman, yakni melakukan pemadamana secara dini di lokasi kejadian apabila terjadi kebakaran hutan dan lahan.

c. Menerima laporan ataupun pengaduan apabila terjadi kebakaran hutan atau lahan dari masyarakat.

d. Melakukan koordinasi kepada para pihak atau Dinas/Instansi terkait yang berkaitan dengan permasalahan penanggulangan dan pemadaman kebakaran hutan dan lahan.

Berdasarkan hasil penelitian tentang Kinerja Tim Serbu Api Kelurahan (TSAK) dalam Penanggulangan Kebakaran Hutan dan Lahan di Kecamatan Sabangau Kota Palangka Raya dapat di jelaskan sebagai berikut :

I. Tujuan

Tujuan merupakan sesuatu keadaan yang lebih baik yang ingin dicapai dimasa yang akan datang. Terkait dengan tujuan utama pembentukan Tim Serbu Api Kelurahan (TSAK) yang ingin dicapai bersama, yakni menanggulangi kebakaran hutan dan lahan masih belum terlaksana sesuai dengan apa yang di harapkan. Hal tersebut kemudian diperkuat lagi oleh jawaban anggota anggota TSAK, bahwa pada dasarnya hampir keseluruhan anggota sudah mengetahui apa yang menjadi tujuan di bentuknya TSAK. Tim Serbu Api Kelurahan sudah semaksimal mungkin melaksanakan penanggulangan kebakaran huatan dan lahan sekecil apapun anggota TSAK tetap selalu berusaha untuk mewujudkan harapan itu agar terlaksana dengan baik walaupun dengan keterbatasan yang dimiliki.

Penanggulangan kebakaran hutan dan lahan yang dilaksanakan oleh Tim Serbu Api Kelurahan masih belum sesuai harapan, masih banyak hal 
yang menjadi penghambat pelaksanaan tugas ketika menanggulangi kebakaran huatan dan lahan, seperti peralatan yang masih kurang memadai dan tidak layak pakai, serta keterbatasa sarana dan prasarana yang dimiliki.

2. Standar

Standar merupakan suatu ukuran pakah tujuan yang diinginkan dapat dicapai. Tanpa standar, tdak dapat diketahui kapan suatu tujuan tercapai. Didalam hasil penelitian bahwasanya Badan Penanggulangan Bencana dan Pemadam Kebakaran (BPBPK) masih belum/ tidak pernah ada membuat Standar Operasional Prosedur yang berkaitan dengan aktifitas pekerjaan, sehingga sangat sulit untuk mengukur/ menentukan keberhasilan suatu pekerjaan. Hal tersebut diperkuat lagi oleh anggota TSAK bahwasanya para anggota TSAK secara pekerjaan sudah memahami yang namanya Standar Operasional Prosedur, namun secara alur untuk menentukan langkah-langkah yang harus diambil agar suatu pekerjaan berjalan sesuai langkah- langkah/ alur para anggota TSAK sangat kesulitan jika apabila terjadi bencana kebakaran hutan dan lahan pada saat operasional dilapangan, ditambah lagi peralatan yang sangat terbatas dan kurang standar, sementara tugas/ pekerjaan masih belum didukung dengan Standar Operasional Prosedur (SOP).

3. Umpan Balik

Umpan balik melaporkan kemajuan baik kualitas maupun kuantitas, dalam mencapai tujuan yang didefinisikan oleh standar. Umpan balik terutama penting ketika kita mempertimbangkan "real goals" atau tujuan sebenarnya. Tujuan yang dapat diterima oleh pekeja adalah tujuan yang bermakna dan berharga. Umpan balik merupakan masukan yang dipergunakan untuk mengukur kemajuan kinerja, standar kinerja, dan mencapai tujuan. Dengan umpan balik dilakukan evaluasi terhadap kinerja dan sebagai hasilnya dapat dilakukan perbaikan kinerja. Didalam hasil penelitian ini terlihat bahwa umpan balik sangat sulit untuk dicapai dan dilakukan, dengan tidak adanya dukungan Standar Operasional Prosedur (SOP) dan sarana/ prasarana yang belum memenuhi standar maka sulit untuk melakukan perbaikan dan kemajuan kinerja.

4. Alat dan Sarana

Alat atau sarana merupakan faktor penunjang untuk pencapaian tujuan. Tanpa alat atau sarana, tugas pekejaan tidak dapat dilakukan dan tujuan tidak dapat diselesaikan sebagaimana seharusnya. Didalam hasil penelitian terlihat bahwa hampir keseluruhan anggota TSAK telah memiliki kemampuan untuk menggunakan peralatan yang sudah diberikan. Sedangkan sarana dan prasarana peralatan yang dimiliki oleh Tim Serbu api Kelurahan (TSAK) masih kurang memadai, sehingga itu juga merupakan faktor yang menjadi kendala mereka tidak bisa melaksanakan pekerjaan menanggulangi kebakaran hutan dan lahan jadi tidak bisa terlaksana dengan baik sesuai dengan apa yang diharapkan. Kurangnya sarana dan prasarana tersebut seperti alat operasional roda tiga sebagai penegangkut anggota dan peralatan menuju lokasi kebakaran sudah rusak dan tidak layak pakai, mesin pompa, selang dan lain sebagainya.

5. Kompetensi

Kompentensi merupakan kemampuan yang dimiliki oleh seseorang untuk menjalankan pekerjaan yang diberikan kepadanya dengan baik. Didalam hasil penelitian ini terlihat bahwa hampir seluruh anggota TSAK memiliki pengetahuan, pemahaman dan kemampuan dalam melaksanakan penanggulangan kebakaran hutan dan lahan. Anggota TSAK seringkali diikutkan dalam pelatihan pengendalian kebakaran hutan dan lahan, sehingga 
dengan penegetahuan yang dimiliki setiap anggota TSAK dalam pelaksanaannya mereka mampu untuk menjalankannya.

6. Motif

Motif merupakan alasan atau pendorong bagi seseorang untuk melakukan sesuatu. Di dalam hasil penelitian bahwa Badan Penanggulangan Bencana dan Pemadam Kebakaran (BPBPK) Kota Palangka Raya tidak pernah menjanjikan/menyediakan kepada Tim Serbu Api Kelurahan (TSAK) berupa kompensasi baik dari segi materil maupun non materil. Badan Penanggulagan Bencana dan Pemadam Kebakaran (BPBPK) tidak mengetahui secara pasti apakah ada atau tidaknya Instansi terkait yang terdahulu ada memberikan semacam kompensasi.

Hal tersebut diperkuat lagi oleh jawaban anggota TSAK, bahwa para anggota TSAK memang pernah menerima Kompensasi dalam bentuk insentiv/honorium penanggulangan pemadaman, namun nilai yang diterima sangat tidak mencukupi untuk kebutuhan hidup seharihari dalam mengemban tugas sebagai anggota Tim Serbu Api Kelurahan (TSAK). Bertolak belakang dengan reori yang menyebutkan bahwa motif merupakan alasan atau pendorong bagi seseorang untuk melakukan sesuatu. Sebelum memberikan tugas/ pekerjaan tujuan yang menantang dan memiliki resiko sangat tinggi, seharusnya pemerintah /Instansi terkait harus memikirkan dan menetapkan standar upah yang seharusnya diterima, dengan demikian hal tersebut akan menjadi faktor pendorong bagi para anggota TSAK untuk melakukan sesuatu yang lebih baik.

7. Peluang

Pekerja perlu mendapatkan kesempatan untuk menunjukan prestasi kerjanya. Terdapat dua faktor yang menyumbangkan pada adanya kekurangan kesempatan untuk berprestasi, yaitu ketersideiaan waktu dan kemampuan untuk memenuhi syarat. Didalam hasil penelitian terlihat bahwa pihak Badan Penanggulangan Bencana dan Pemadam Kebakaran (BPBPK) Kota Palangka Raya tidak ada memberikan harapan kepada anggota TSAK, baik itu prestasi ataupun masa depan, sebab anggota TSAK dibentuk bukan sebagai profesi tetapi tujuan sebenarnya adalah sosial dan kemanusiaan, namun Badan Penanggulangan Bencana tetap berusa untuk mencari solusi agar keninerja dan kehidupan anggota TSAK menjadi lebik baik lagi.

\section{KESIMPULAN}

Kinerja Tim Sebu Api Kelurahan Di Kecamatan Sebangau Kota Palangka Raya masih belum maksimal, berdasarkan beberpa infikator penilaian kinerja menunjukkan bahaw tujuan yang ingin dicapai bermsa dengen Badan Penangglangan Bencana dan Kebebaran masih belum terlaksanan sesuai harapan. Hal ini karena dalam pelaksanaan tugasnnya masih belum didukung dengan Standar, diatandai dengan tidak adannya Standar Operasional Prosedur. Dengan tidak adanya SOP maka sulit untuk dilakukan perbaikan dan kemajuan karena tidak ada umpan balik uang dihasilkan. Permasalahan yang menjadi penghambat adalah alat operasional yang masih belum memadai sehingga pelaksanaan tugas tidak maksimal. Padahal sumber daya manusia yang ada sudah memiliki pengetahuan, pemahaman dan kemampuan dalam mealaksnakan penanggulangan kebarakaran hutan dan lahan.

\section{REFERENSI}

Afrizal. 2014. Metode Penelitian Kualitatif. Jakarta: Rajawali Pers.

Fahmi, Irham. 20I0. Manajemen Kinerja, teori dan aplikasi. Bandung: CV Alfabeta.

Mahmudi. 2005. Manajemen Kinerja Sektor Publik. Yogyakarta: UPP STIM YKPN. 
Mangkunegara, Anwar Prabu. 2005. Evaluasi Kinerja SDM. Bandung: PT Refika Aditama.

Pasolong, Harbani. 2007. Teori Administrasi Publik. Bandung: CV Alfabeta.

Sedarmayanti. 2007. Manajemen Sumber Daya Manusia, reformasi birokrasi dan manajemen pegawai negeri sipil. Bandung: PT Refika Aditama.

Sugiyono. 2007. Metode Pnelitian Administrasi. Bandung: CV Alfabeta.

Sinambela, Lijan Poltak. 2006. Reformasi Pelayanan Publik, teori, kebijakan dan implementasi. Jakarta: PT Bumi Aksara.

Sinambela, Lijan Poltak. 2012. Kinerja Pegawai, Teori, Pengukuran dan Implikasi. Yogyakarta: Graha IImu.

Wibowo. 20I4. Manajemen Kinerja. Jakarta: PT RajaGrafindo Persada. 